Ethos : Jurnal Penelitian dan Pengabdian kepada Masyarakat, Vol 7, No.1, Januari 2019: 101-107

\title{
Peningkatan Kesejahteraan Ekonomi Melalui Perilaku Hidup Sehat dan Bersih Pada Anak dan Pengelola Panti Asuhan Tebet
}

\author{
${ }^{1}$ Rutinaias Haholongan, ${ }^{2}$ Syahrul Effendi, ${ }^{3}$ Said Khaerul Wasif, ${ }^{4}$ Erni Rohmawati \\ ${ }^{1,2,3,4}$ Fakultas Ekonomi Sekolah Tinggi Ilmu Ekonomi Indonesia Jakarta \\ E-mail: ${ }^{1}$ rutinaias@gmail.com
}

\begin{abstract}
Community service to improve the welfare and awareness of Tebet's orphanage children in maintaining health and cleanness. Community service activities that require ways to improve welfare through the environment and wash hands. Activities carried out at the tebet orphanage run smoothly with the hope that orphanage children can practice the material that has been delivered, specific patterns of maintaining personal hygiene and the environment, and welfare can be improved. Managers and orphanage children are aware of the importance of maintaining personal hygiene, this is evidenced by washing hands before eating. In addition students will also clean the environment envisioned by students to sweep the yard, outside the orphanage

Keywords : economic welfare, healthy and clean living behavior, orphanages, hand washing.
\end{abstract}

\begin{abstract}
Abstrak. Pengabdian masyarakat bertujuan untuk meningkatkan kesejahteraan dan kesadaran pengelola anak panti asuhan Tebet dalam menjaga berprilaku hidup sehat dan bersih. Kegiatan pengabdian kepada masyarakat berupa penyuluhan bagaimana cara meningkatkan kesejahteraan ekonomi melalui dengan membersihkan lingkungan dan mencuci tangan. Kegiatan dilakukan di panti asuhan tebet berjalan dengan lancer dengan harapan yaitu anak panti asuhan dapat mempraktekkan materi yang telah disampaikan,khususnya pola menjaga kebersihan diri dan lingkungan, sehingga kesejahteraan ekonomi panti asuhan dapat meningkat. Pengelola dan anak panti asuhan sadar akan pentingnya menjaga kebersihan diri, hal ini dibuktikan dengan adanya cuci tangan sebelum makan. Selain itu siswa juga sadar akan pentignya kebersihan lingkungan dibuktikan dengan siswa sadar untuk menyapu halaman, ruangan panti asuhan.
\end{abstract}

Kata Kunci : Kesejahteraan ekonomi, perilaku hidup sehat dan bersih, panti asuhan, cuci tangan.

\section{Pendahuluan}

Kesejahteraan ekonomi panti asuhan belum memadai, ditandai dengan rendahnya kesadaran pengelola dan anak - anak panti asuhan untuk menjaga perilaku hidup bersih dan sehat, disebabkan pengeluaran semakin hari semakin besar. Adanya kondisi anak panti asuhan yang belum mengerti cara menjaga hidup sehat dan bersih, disekitar panti asuhan masih terdapat hunian warga yang tidak layak. Dalam menerapkan budaya sehat dan bersih, pengelola dan anak panti asuhan harus mampu menerapkan lingkungan yang bersih untuk kelangsungan hidup baik pengelola maupun anak panti asuhan dan juga sehat dalam arti mandiri secara ekonomi.

Perilaku hidup yang tidak sehat dapat menimbulkan permasalahan bagi 
masyarakat, terutama pada anak usia sekolah. Rahmawati (2008) menyampaikan bahwa W.H.O telah mengidentifikasi diare sebagai penyebab balita mengalami kematian menempati nomor satu sedangkan saluran pernafasan akut (ISPA) penyebab kematian diposisi nomor dua. Penyakit infeksi parasit cacing juga merupakan salah satu masalah besar bagi masyarakat terutama pada negeri berkembang dan negara miskin. Dua milyar orang terinfeksi penyakit ini dan penyakit ini menyebar di pedesaan dan perkotaan.

Kesehatan anak merupakan salah satu unsur kesehatan yang terpenting, karena masa 0-6 tahun merupakan usia emas yang usia ini anak mengalami perkembangan fisik, motorik, emosional, intelektual, bahasa dan sosial berlangsung sangat cepat (Siswanto, 2009). Peningkatan pemeliharaan kesehatan sangat penting karena kualitas anak sangat dipengaruhi oleh kesehatan semasa tumbuh kembang anak. Kondisi yang lebih sehat sejak usia anak akan member kesempatan tumbuhnya sumber daya manusia yang sehat dan berkualitas di masa depan.

Panti Asuhan Tebet berada di daerah pemukiman padat penduduk dan dekat pedagang makanan kecil dan jajanan masih berjualan di sekitar lingkungan. Berdasarkan pengamatan, selalu ada siswa yang membeli makanan di luar lingkungan Panti Asuhan Tebet pada setiap jam istirahat. Fasilitas yang tersedia masih belum mendukung terlaksananya program perilaku hidup sehat. Sebenarnya sudah ada wastafel dan toilet untuk menunjang program perilaku hidup bersih namun ketika dilakukan pengecekan ternyata wastafel yang tersedia tidak terawat, toilet kotor dan kurang terawat. Lingkungan Panti
Asuhan Tebet jauh dari hal kebersihan karena masih banyak sampah berceceran dan fasilitas tempat sampah yang masih minim.

Menurut Tumiwa (2015), perilaku hidup bersih dan sehat terdapat 3 faktor meliputi: 1) Predisposing factor, menjadi dasar pemicu pengetahuan dan sikap terhadap hidup sehat. 2) Enabling factor, dasar pemicu motivasi atau tindakan terlaksana, meliputi fasilitas kesehatan, ketersediaan lingkungan bersih, tersedianya makanan bergizi, tempat pembangan sampah untuk mewujudkan hiudp sehat dan bersih. 3) Reinforcing factor menentukan faktor dukungan bisa didapatkan dari tenaga kesehatan berupa penyuluhan, tokoh masyarakat setempat berupa himbauan, atau pemerintah berupa kebijakan.

Tujuan kegiatan ini adalah meningkatkan kesejahteraan ekonomi pengelola dan anak - anak Panti Asuhan Tebet dan Menghimbau anak - anak panti asuhan untuk menjaga kebersihan di lingkungan Panti Asuhan Tebet.

\section{Metode Pengabdian}

Dalam kegiatan pengabdian kepada masyarakat di panti asuhan tebet tim mengunakan observasi, metode ceramah, diskusi, tanya jawab, pre-post test dan simulasi praktik. Observasi lapangan dilakukan baik sebelum kegiatan dimulai, sedang berlangsung, maupun setelah sebagian kegiatan selesai. Kegiatan dilakukan setelah ada kesepakatan dengan pihak pengelola panti asuhan. Kriteria peserta yang mengikuti kegiatan yaitu anak usia antara 4-12 tahun, hal ini dikarenakan anak di rentang usia tersebut belum memperhatikan hidup bersih dan sehat dan pengelola panti asuhan yang nantinya dapat membimbing dan 
mengingatkan anak-anak untuk menjaga kebersihan diri dan lingkungan secara berkesinambungan. Total jumlah peserta tiga puluh enam orang.

Selanjutnya, perencanaan kegiatan ini mengacu pada pola manajemen suatu kegiatan. Perencanaan, menurut Suryabrata (2014), adalah pemilihan prosedur, program dan penentuan strategi dan standar yang diperlukan untuk mencapai tujuan. Dalam kegiatan ini perencanaan dilakukan berdasarkan analisis kebutuhan langkah-langkah proses kehumasan yang diawali dengan fact finding (pencarian fakta melalui analisis situasi lingkungan). Setelah didapatkan data, disusunlah agenda kegiatan yang dilakukan oleh tim sebagai berikut:

Tabel 1. Susunan Acara PKM

\begin{tabular}{|c|c|c|}
\hline Waktu & Kegiatan & Pelaksana \\
\hline $13.00-13.15$ & Registrasi & Tim \\
\hline $13.15-13.30$ & Pembukaan & $\begin{array}{l}\text { Ketua Panitia dan Pengelola } \\
\text { Panti Asuhan }\end{array}$ \\
\hline $13.30-14.00$ & Materi Peningkatan kesejahteran ekonomi & Erni Rohmawati, SE, M.Ak. \\
\hline $13.30-14.30$ & Materi Konsep hidup Sehat dan bersih & Novida Rewaty \\
\hline $14.30-15.00$ & $\begin{array}{l}\text { Pembelajaran hidup sehat dan bersih melalui } \\
\text { Video Animasi }\end{array}$ & $\begin{array}{l}\text { Rutinaias Haholongan, SE, } \\
\text { M.M }\end{array}$ \\
\hline $15.00-15.30$ & Sholat dan coffe break & \\
\hline $15.30-16.30$ & Praktek hidup sehat dan bersih & $\begin{array}{l}\text { Novida Rewaty } \\
\text { Rutinaias Haholongan, } \\
\text { S.E,M.M } \\
\text { Erni Rohmawati, SE, M.Ak. } \\
\text { Syahrul Effendi, S.E., M.M } \\
\text { Tim }\end{array}$ \\
\hline
\end{tabular}

Metode ceramah dan diskusi yang digunakan dikegiatan. Ceramah dilakukan untuk memberikan materi yang didiskusikan serta menginformasikan pentingnya menjaga polah hidup sehat dan bersih yang berkualitas. Menurut Suryabrata (2014), metode ceramah adalah sebuah bentuk interaksi melalui penerangan dan penuturan lisan dari pemateri kepada peserta. Ceramah merupakan bentuk cara belajar yang bersifat searah menekankan pada pemberitahuan informasi dari pemateri kepada peserta yang aktif dan pasif. Diskusi merupakan pola tukar pikiran tentang suatu masalah untuk mencapai tujuan melalui analisis, memecahkan masalah, menggali, atau memperdebatkan suatu topic antara dua orang atau lebih. Seusai diskusi, peserta diminta untuk latihan mencuci tangan dan menggosok gigi yang benar. Setelah melakukan praktek mencuci tangan dan menggosok gigi, kegiatan dilanjutkan dengan pengisian kuesioner oleh peserta dan pemberian bingkisan.

\section{Hasil dan Pembahasan}

Kegiatan pelatihan peningkatan kesejahteraan ekonomi melalui perilaku hidup sehat dan bersih pada anak dan pengelola panti asuhan tebet dilaksanakan di panti asuhan tebet. Kegiatan tersebut dibuka tepat jam 13.00 WIB, oleh ketua pelaksana dan pengelola panti asuhan tebet. Kegiatan 
ini dihadiri 6 pengelola dan 30 orang peserta anak panti asuha tebet.

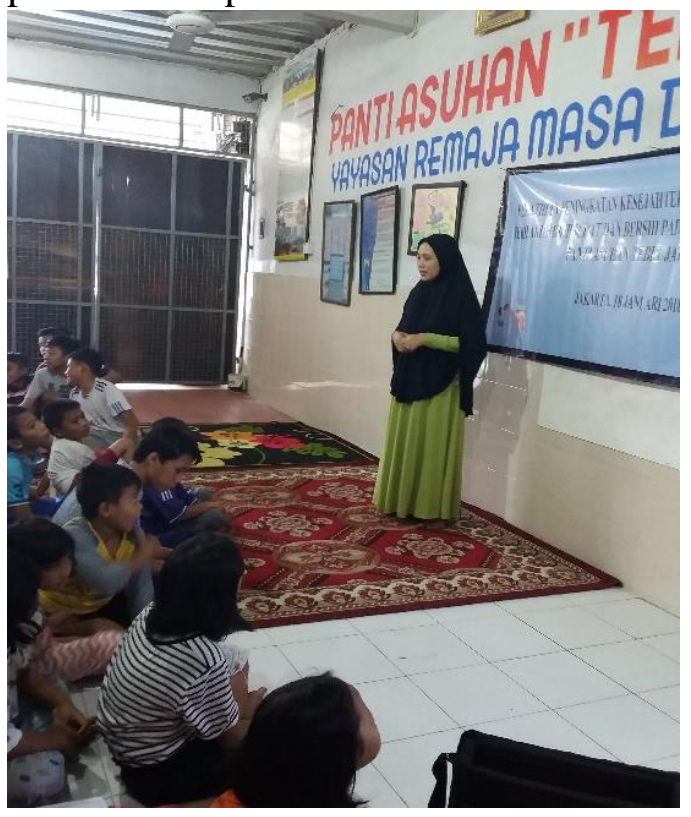

Gambar 1. Pembukaan Pelatihan Peningkatan Kesejahteraan Ekonomi Melalui Perilaku Hidup Sehat dan Bersih Pada Anak dan Pengelola Panti Asuhan Tebet

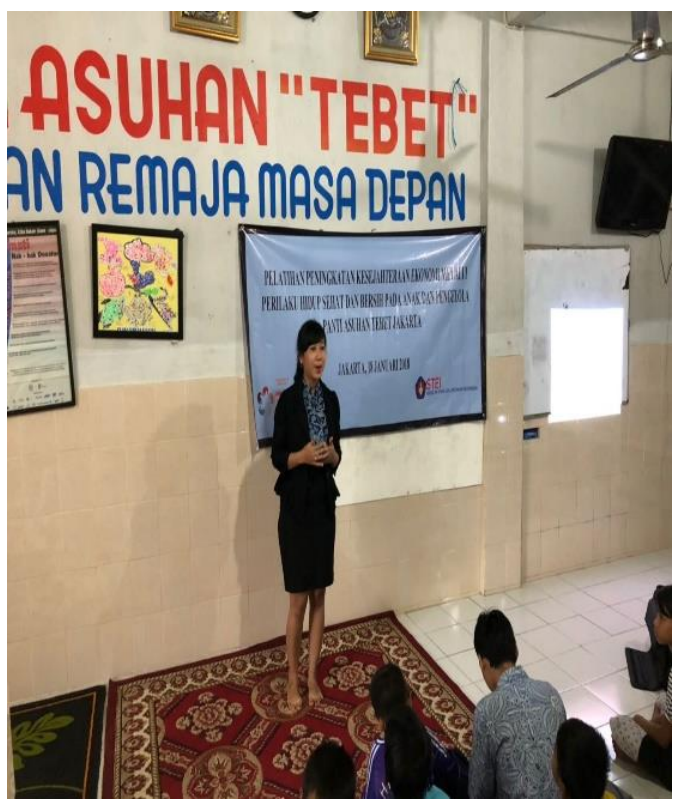

Gambar 2. Pelatihan Peningkatan Kesejahteraan Ekonomi

Pada sesi pertama dipaparkan peningkatan kesejahteraan ekonomi. Peningkatan kesejahteraan anak dan pengelola panti dimulai dari unit terkecil yaitu dari menjaga kebersihan tubuh dan lingkungan panti. Dalam mensejahterakan anak dan pengelola panti diperlukan mengembangakan beberapa indikator untuk mengukur tingkat kesejahteraan panti asuhan tebet dengan menggunakan indikator ekonomi , kesehatan gizi, dan sosial. Tujuan meningkatkan kesejateraan ekonomi yaitu:

1. Dapat memenuhi kebutuhan sosial psikologi anak panti seperti kebutuhan akan pendidikan

2. Seluruh anak panti memiliki pakaian sekolah maupun dirumah yang bersih

3. Bila anggota panti asuhan sakit segera dibawa ke sarana kesehatan.

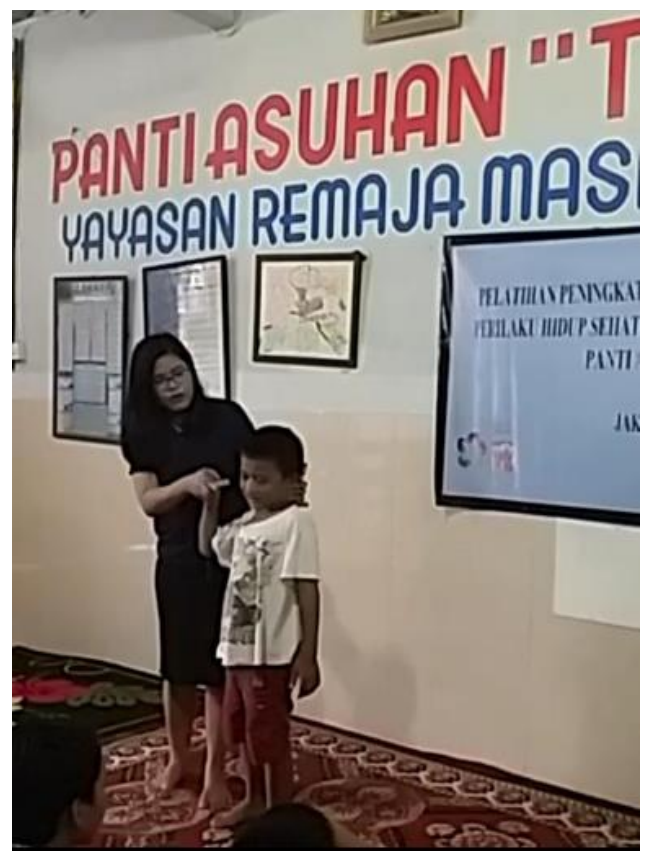

Gambar 3. Pelatihan Konsep Perilaku hidup Sehat dan bersih

Pada sesi kedua pelatihan konsep perilaku hidup sehat dan bersih,. Kegiatan diawali instruktur mengeluarkan alat alat kebersihan badan seperti sikat gigi, pasta gigi, sabun. Setelah itu, instruktur memaparkan 
metode atau cara yang dapat digunakan untuk menggunakan perlatan kebersihan badan yang baik dan benar, Instruktur mengajak peserta maju kedepan untuk memperagakan gerakan sikat gigi yang baik dan benar.

Pada sesi ke tiga pembelajaran perilaku hidup sehat dan bersih melalui video animasi. Kegiatan diawali instruktur memutar video animasi kesehatan tubuh tentang dampak makan jajan sembarangan dan mencucui tangan. Anak dan pengelola panti sangat antusias menonton film animasi yang berdurasi pendek. Setelah selesai pemutaran video, dijelaskan kembali oleh instruktur, betapa pentingnya menjaga kebersihan badan dan lingkungan. Lingkungan dan tubuh yang sehat membuat anak - anak panti nyaman untuk bermain dan belajar.

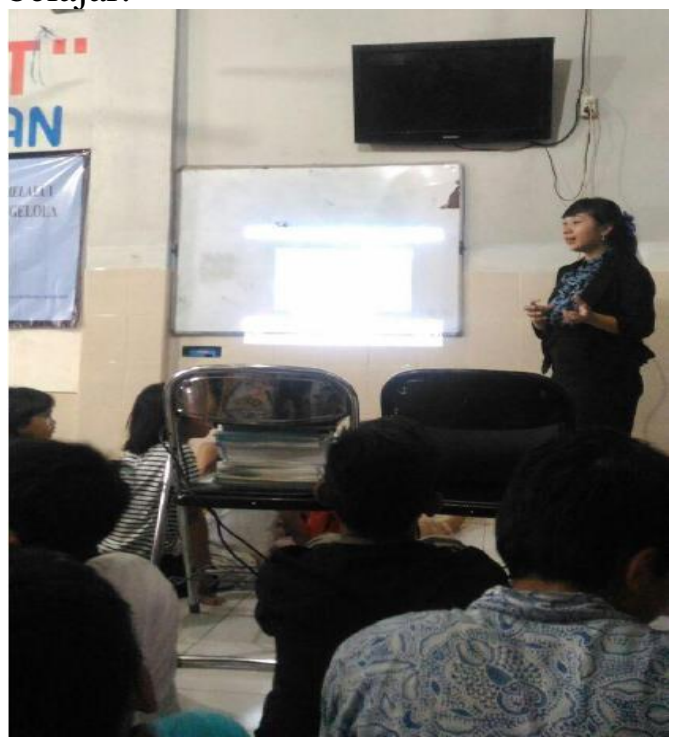

Gambar 4. Pembelajaran perilaku hidup sehat dan bersih melalui Video Animasi

Setelah Ishoma, kegiatan dilanjutkan dengan sesi ke empat, yaitu praktek membersihkan gigi dan mencuci tangan yang benar. Kegiatan diawali instruktur Ibu Novida Rewaty memberikan aba - aba gerakan mencuci tangan diikuti oleh anak anak panti dan pengelola panti beserta pegawainya, semua menirukan gerakan ibu novida rewaty dengan baik. Setelah selesai mempraktekkan cara mencuci tangan yang benar Ibu novida rewaty memcontohkan sikat gigi yang baik dan benar diikuti peserta anak dan pengelola panti. Pelatihan ini mendapat apresiasi yang sangat baik dari peserta. Antusiasme dan tingginya minat peserta mengikuti pelatihan, menjadikan suasana pelatihan sangat menyenangkan.

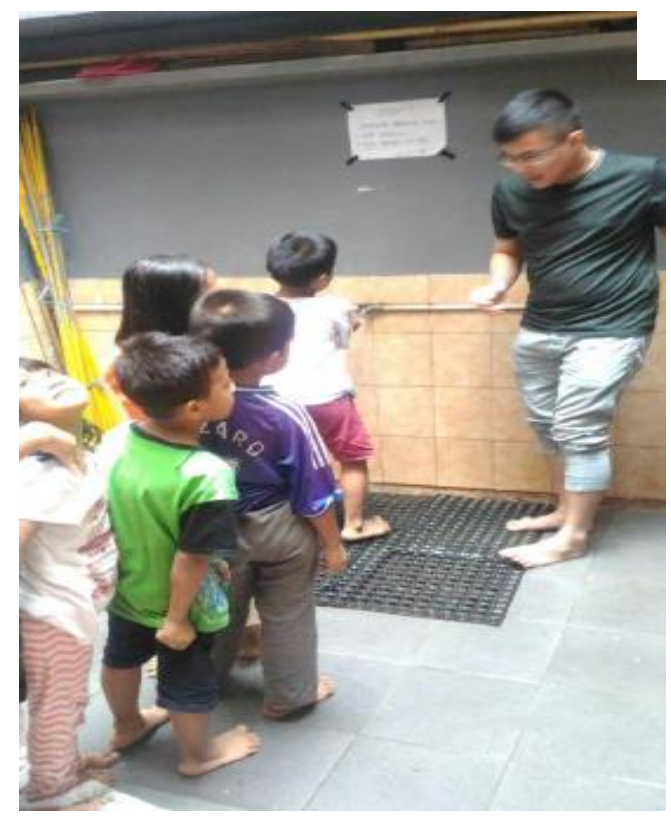

Gambar 5. Praktek Hidup Sehat dan Bersih

Setelah melakukan praktek mencuci tangan dan menggosok gigi, kegiatan dilanjutkan dengan pengisian kuesioner oleh peserta. Berikut tabulasi jawaban peserta dapat dilihat pada Tabel 1.

Secara umum, seluruh peserta pengelola panti menyatakan bahwa kegiatan Pelatihan peningkatan kesejahteraan ekonomi melalui perilaku hidup sehat dan bersih pada anak dan pengelola panti asuhan tebet sesuai dengan kebutuhan mereka dan materi yang disampaikan mudah untuk 
dipahami, serta mereka akan menceritakan kegiatan tersebut ke orang-orang di sekitar. Namun, ada dua peserta yang menyatakan penyuluhan tersebut belum memotivasi mereka untuk meningkatkan kesejahteraan ekonomi dengan hidup sehat dan bersih , dan 1 orang belum tahu kapan akan meningkatkan kesejahteraan ekonomi dengan hidup sehat dan bersih

Tabel 1. Tabulasi Jawaban Pengelola

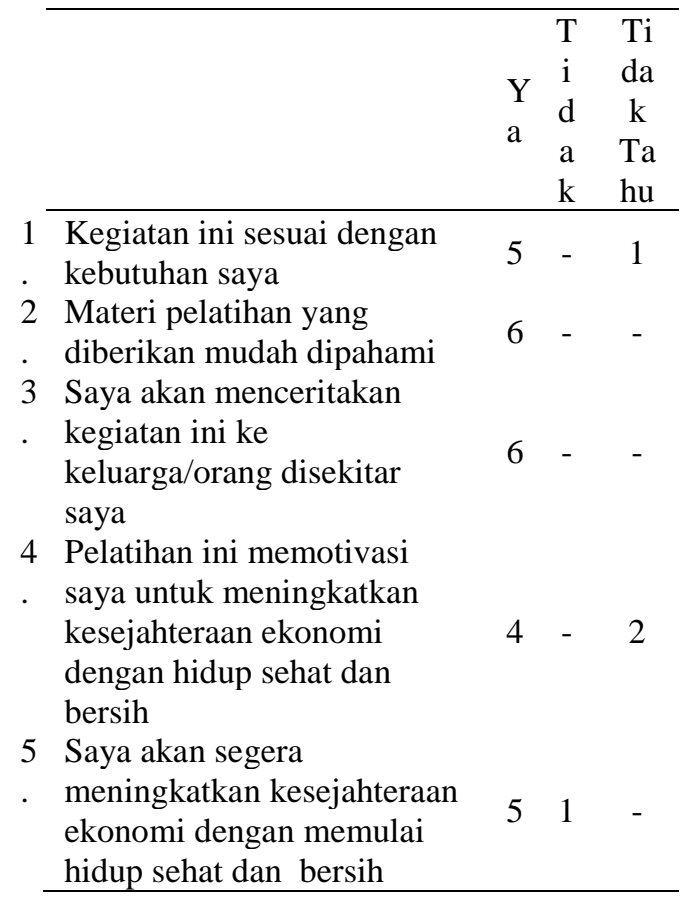

Berdasarkan saran, sebagian besar peserta menginginkan kegiatan peningkatan kesejahteraan ekonomi melalui perilaku hidup sehat dan bersih pada anak dan pengelola panti asuhan tebet agar dilanjutkan, namun dengan jenis topik kesehatan yang berbeda. Harapan merekea kegiatan-kegiatan seperti ini semakin memacu dan membina kemampuan dalam meningkatkan perekonomian panti asuhan dengan menjaga pola hidup sehat dan lingkungan yang bersih

\section{Simpulan Dan Saran}

\section{Simpulan}

Kegiatan yang dilaksanakan di Panti Asuhan tebet berjalan dengan baik dan lancar, dengan harapan yaitu pengelola dan anak panti asuhan dapat menerapkan materi yang telah disampaikan dengan menjaga kebersihan diri dan lingkungan untuk meningkatkan kesejahteraan ekonomi Panti Asuhan Tebet. Anak - anak panti asuhan sadar akan pentingnya menjaga kebersihan diri, hal ini dibuktikan adanya cuci tangan dan kebersihan lingkungan dengan menyapu halaman panti

\section{Saran}

1. Bagi anak - anak panti asuhan diharapkan membiasakan untuk berperilaku bersih supaya dapat terhindar dari berbagai penyakit yang diakibatkan lingkungan yang tidak bersih.

2. Bagi pengelola panti diharapkan memberikan bimbingan kepada anak panti agar menyadari bahwa memelihara hidup bersih bukan saja penting bagi diri sendiri tetapi juga baik untuk keluarga. Namun sadar juga tidak cukup, anak juga harus dituntun agar mempunyai kemauan untuk melakukan sesuatu baik untuk dirinya sendiri.

\section{Ucapan Terima Kasih}

Tim mengucapkan terima kasih kepada Pusat Pemberdayaan Masyarakat(PPM), Lembaga Penelitian dan Pengabdian kepada Masyarakat (LPPM), Sekolah Tinggi Ilmu Ekonomi Indonesia Jakarta yang telah memberikan bantuan dana. Tim juga menyampaikan terima kasih kepada 
Pengelola Panti Asuhan Tebet atas kesempatan dan tempat yang diberikan sehingga kegiatan pengabdian ini dapat berlangsung dengan baik.

\section{Daftar Pustaka}

Rahmawati, Elfy. 2008. Analisis

Kebutuhan Program Promosi

Pencegahan Diare pada Anak

Dibawah Usia Dua Tahun. Jurnal

Berita Kedokteran Masyarakat.

Siswanto, Hadi. 2009. Pendidikan

Kesehatan Anak Usia Dini. Pustaka

Rihana: Jakarta.

Suryabrata, S. 2014. Metodologi

Penelitian. Jakarta : Rajawali Press

Tumiwa, Finny F., A. J. M. Rattu, A. A.

T. Tucunan. 2015. Hubungan Antara

Faktor Predisposing, Enabling, Dan

Reinforcing Dengan Perilaku Hidup

Bersih Dan Sehat Tatanan Rumah

Tangga Di Kecamatan Remboken

Kabupaten Minahasa. Jurnal

Kedokteran Klinik Universitas Sam

Ratulangi 